\title{
OVERVIEW ON ANALYSIS OF FREE METABOLITES FOR DETECTION OF EXPOSURE TO CHEMICAL WARFARE AGENTS
}

\author{
Nicoleta GRIGORIU* \\ grig_nicole@yahoo.com \\ Gabriel EPURE* \\ gabriel.epure@nbce.ro \\ Dănuţ MOŞTEANU** \\ dmosteanu@gmail.com \\ * SCIENTIFIC RESEARCH CENTER FOR CBRN, DEFENCE AND ECOLOGY, BUCHAREST \\ ** “NICOLAE BĂLCESCU” LAND FORCES ACADEMY, SIBIU, ROMANIA
}

\begin{abstract}
Chemical warfare agents (CWA's) induce complex toxicological effects with major adverse consequences for those exposed. For many chemical agents there is a need for research and development of analytical toxicological methods for a rapid and certain confirmation of those exposures. The certain methods will help for establishing the laboratory diagnosis for applying the proper therapy; the treatment of only contaminated people, decreasing the stress level in the medical community in management of crisis situations, increasing the survival rate of the population exposed to the contamination, supervision of professional exposure, judicial analysis in case of suspicious terrorist activities.

The paper presents some analytical toxicological methods for detection, identification and confirmation of metabolites from urine samples, based on the metabolism/hydrolysis processes of CWA's.
\end{abstract}

\section{Keywords}

CWA's, detection, urinary metabolits, diagnosis, contamination

\section{Introduction}

The confrontation of mankind over time with terrorist attacks having the greatest threatening potential, CWA's, mainly the nerve and vesicant agents, leads to the development of methods of investigation for rapid confirmation of these exposures. The chemical warfare agents were mainly used against the civilian population, for example, the nerve agents were used in attacks by the Iraqi people against the Kurdish population, the vesicant 
agent (sulfur mustard gas) was used in the conflict between Iran and Iraq during the Gulf War (1980-1988; tens of thousands victims) [1], the sarin nerve agent was used in the 2 attacks organized by the Aum Shinrikyo cult in Matsumoto, Japan (1994; 8 victims and 274 persons affected) and in Tokyo, Japan (1995; 12 victims and over 5000 hospitalized persons, including civil protection and medical personnel), the VX assassination in Osaka, Japan (1994) [2, 3].

When the first conflicts from modern times occurred (the Iraq-Iran conflict) when CWA's were widely used, there were no validated procedures available for biomedical sample analysis. In the next two decades, various methods for detecting the nerve and vesicant agents have been reported in the scientific literature, otherwise available only in a few laboratories from the whole world. The analytical methods successfully used to detect exposure to CWA's in human cases have been reported when using the nerve and vesicant agents in the conflicts between Iraq and Iran and Iraq-Kurdistan [4-6], the sarin attack in Matsumoto [7] and Tokyo [8], the VX assassination in Osaka [9] or in the case of accidental poisoning [10].

In such cases, taking the emergency measures involves the knowledge and evaluation of the nature of the contamination, the resulted effects, the degree of risk and the immediate and effective countermeasures. The environmental sampling (water, soil, vegetation, clothing, etc.) and biological samples (urine, blood, tissue, etc.) immediately after the event occurred, will provide critical information and will save lives, in case of subsequent contamination and thus, will act beneficial to the environment.

The majority of CWA's have electrophilic reactive groups which react with different degrees of reactivity and selectivity, with the organic groups having nucleophilic nature, in the enzyme-catalyzed hydrolysis reactions, resulting free metabolites excreted then into urine [1]. When the free metabolites are formed, covalently bonded compounds are also formed by nucleophilic structural spaces of macromolecules (such as proteins: hemoglobin, albumin, cholinesterase) or DNA, bearing the name of adducts. These adducts may remain for a long time in the blood and tissues (even for several months), depending on the alteration degree of the metabolic processes, thus offering a potential for investigation much longer after the exposure, as compared to the free metabolites. Both the free metabolites and the covalently bound adduct represent, unquestionably, the biomarkers responsible for exposure of a certain population to the action of the CWA's.

\section{Nerve Agents}

The nerve agents have the highest toxic potential from all the CWA's [11] declared to the OPCW [12] being the most studied compounds by the international scientific community. The nerve agents are classified into three structural classes, type $\mathrm{G}$ agents: sarin (military designation: GB), soman (GD), cyclosarin (GF), type V agents: VX (USA) and RVX (Russia), shown in Figure no. 1 [1] and tabun (GA) in Figure no. 2 [1].

\subsection{Distribution and Metabolism of Nerve Agents}

Nerve agents can enter the body not only through the respiratory system, but also through the pores of the skin. Their toxic effect is due to the fact that it blocks the parasympathetic nervous system by inhibiting the acetyl cholinesterase enzyme. This leads to the rapid accumulation of acetylcholine, substance used in the transmission of nerve impulses through synapses, which is normally blocked by cholinesterase, few milliseconds after its production. The effect is to disrupt the transmission of nerve impulses to the central nervous system and also the junction between nerves and muscles. As a result, there are contractions of smooth muscle fibers, convulsions and respiratory arrest.

The primary route of elimination from the body of nerve agents (type $\mathrm{G}$ and $\mathrm{V}$ ) is the enzymatic hydrolysis reactions (Figure no. 1). The main resulted metabolite is the 
alkylmethylphosphonic acid (1). The studies reported until present relate almost exclusively to type $\mathrm{G}$ and $\mathrm{V}$ agents, very few references are reported for tabun agent. No real cases of exposure have been reported for tabun [1].
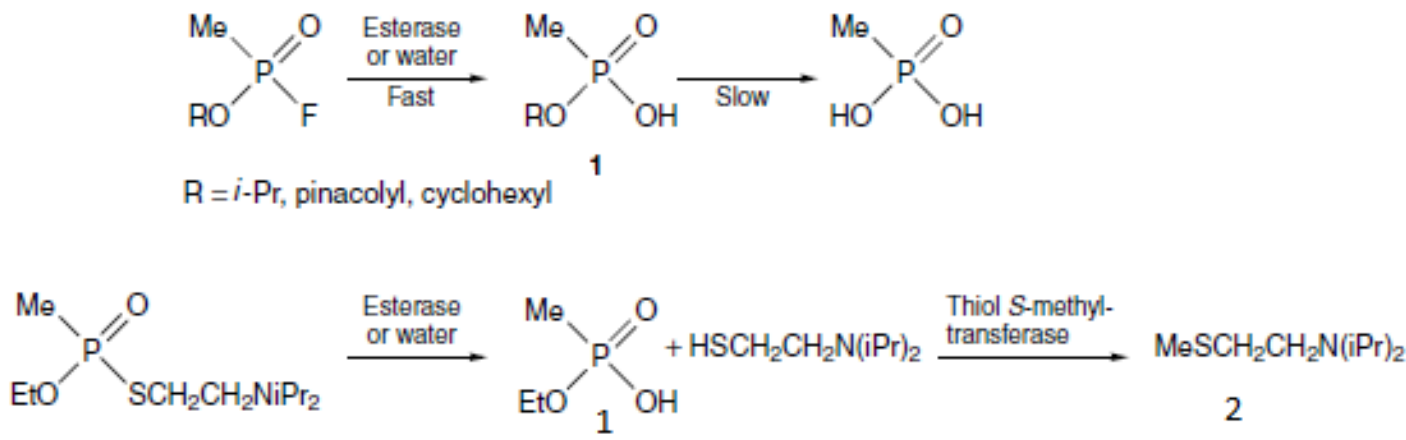

Figure no. 1 Metabolism and/or hydrolysis pathway of type $G$ and V nerve agents [1]

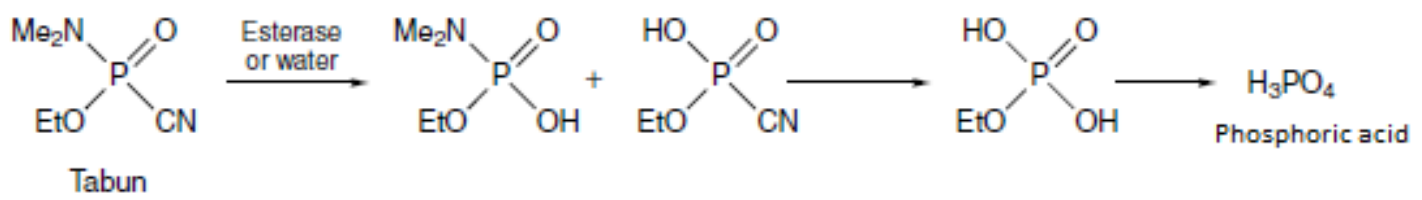

Figure no. 2 Metabolism and/or hydrolysis pathway of tabun nerve agent [1]

\subsection{Analytical Methods for Nerve Agents and Their Metabolites}

In order to demonstrate the exposure to CWA's, mass spectrometry is the most widely used analytical technique, especially in chemistry and judicial toxicology. The majority of the metabolites are small molecules, relatively polar, that can be analyzed by gas chromatography coupled with mass spectrometry (GC/MS) techniques, normally after having applied the derivatization techniques, or in an underivatized form by liquid chromatography coupled with mass spectrometry (LC/MS ).

In the scientific literature, a limited number of procedures were reported for the isolation of free metabolites such as alkylmethylphosphonic acid in blood and urine samples, by solid phase extraction technique (SPE). However, due to differences in hydrophobicity of alkylmethylphosphonic acids the selective use of SPE cartridges is imposed. If for the isolation of isopropyl methylphosphonate (sarin metabolite) C18 SPE cartridges are efficient, for acids with a higher hydrophobicity as the pinacolyl methylphosphonate (soman metabolite) and cyclohexyl methylphosphonate (cyclohexyl sarin metabolite) C2 SPE cartridges have proven to be efficient as far as extraction is concerned. The SPE techniqu requires a series of specific phases, namely the conditioning, washing the cartridge, the extraction phase (elution) of the analyte with a suitable solvent. Once the compound of interest is isolated and assumed, the process continues with the concentration phase of the eluting solvent, the derivatization and purification of the metabolite isolated on a Florisil SPE cartridge. The procedures imply a significant number of sample preparations, a source of error, contamination and loss of metabolites, found already at trace levels. A more simplified procedure involves the use of a polymer extraction cartridge, the elution and derivatization after dry concentration or directly in the eluted.

Other methods for detection of free metabolites reported in the scientific literature involve the conversion to ester trimethylsilyl (TMS) and tert-buthyldimethylsilyl 
(TBDMS), after expensive phases of biological sample preparations.

\subsection{Detection in Cases of Human Poisoning}

The high levels of the sarin metabolites, detected as TBDMS esters and analyzed by gas chromatography with flame-photometric detector (GC/FPD) have been reported in the urine samples of the victims of Matsumoto [7], together with the dramatic decrease of acetylcholinesterase activity. Isopropyl methylphosphonate metabolite was detected as TMS ester and analyzed by GC/FPD in the urine samples collected after 7 days after the terrorist attack in Tokyo [13]. The estimated concentrations were 0.13 to $0.25 \mathrm{mg}$ of sarin at patients in coma and 0.016 to $0.032 \mathrm{mg}$ in patients with less severe poisoning.

The main metabolite of VX nerve agent, respectively ethyl methylphoshonate (EMPA) was detected as TBDMS ester by GC/MS and GC/MS/MS analysis, in the serum sample of the person killed by VX [9, 14]. A concentration of $1250 \mathrm{ng} / \mathrm{ml}$ was estimated in the blood sample collected after one hour from the occurrence of the assassination and stored for several months at $-20{ }^{\circ} \mathrm{C}$. The compound 2 from Figure 1 described above, and 2 - (diisopropylaminoethyl)-methyl sulfide, derivate from the enzymatic methylation of the sulfur atom of the hydrolysis product $\mathrm{HSCH}_{2} \mathrm{CH}_{2} \mathrm{~N}$ (i-Pr) $)_{2}$, was identified in the human serum by a process of extraction and analysis through GC/MS. The concentration was estimated to $143 \mathrm{ng} / \mathrm{ml}$. The identification of this metabolite clearly distinguishes the exposure to VX and the exposure to sarin counterpart (O-ethyl methylphosphonofluoridate).

\section{Vesicant Agents}

The vesicant agents are oily liquids that attack all living tissue by destroying the cell structure. In a period of time ranging from a few hours to a few days, blisters and severe burns appear healing slowly due to blocking the cellular and mitotic respiration. Despite the large number of injuries observed during the First World War and all investigations that followed, vesicant process mechanism is still not well known [1]. It is assumed that the vesicant agents react with the carbonyl groups, amino and sulfhydryl from proteins. Vesicant agents have a high potential to be used by less developed countries or by the terrorist organizations. The ease with which one can produce them, coupled with their effectiveness against an unprotected population present the arsenic compounds as an ongoing threat of the $21^{\text {st }}$ century.

Although tons of lewisite and mustard gas-lewisite mixtures lie now in unknown places as old chemical weapons left after the Second World War (Koryagina et al., 2011), these chemical warfare agents have not undergone scientific research during the last decade. The scientific literature on sensitive detection methods of biomarkers specific to lewisite in the biomedical samples is very poor, the existing reports being based on a limited number of in vitro experiments (Jakubowski et al., 1993; Wooten et al., 2002) and in vivo researches (Logan et al., 1999; Fidder et al., 2000, Koryagina et al., 2006, Stanelle et al., 2010).

\section{Lewisite \\ 3.1. Distribution and Metabolism of}

Lewisite hydrolyses to form 2chlorovinylarsonous acid (CVAA), presented in Figure 3, which is the hydrated form of 2chlorovinylarsine oxide and exists exclusively in aqueous solution. CVAA can be further oxidized to 2-chlorovinylarsonic acid (CVAOA). These two acids are lewisite markers, i.e., their detection in biomedical samples provides unequivocal evidence for exposure to lewisite. Both CVAA and CVAOA still retain the toxic properties of lewisite, albeit at lower potency (Munro et al., 1999). The toxicological experiments conducted by Koryagina and her collaborators [15] (the exposure of laboratory animals to lewisite with and without antidotal treatment) showed the potential of the urine samples as universal matrix, preferred for the detection of 
lewisite biomarkers. Blood samples, Koryagina said, can be a perspective matrix to confirm the results obtained in the analysis of urine samples.

\subsection{Analytical Methods for Lewisite and Their Metabolites}

Jakubowski et al. [16] developed a GC/MS method for CVAA spiked into guinea pig urine using 1,2-ethanedithiol for derivatization, with phenyl arsine oxide as the internal standard. The same group later expanded the method to include atomic emission detection (AED) [17]. CVAA was concentrated from urine (adjusted to $\mathrm{pH} 6$ with $1 \mathrm{M} \mathrm{HCl}$ ) by SPE on $\mathrm{C}_{18}$. After elution with methanol and concentration to dryness, the residue was reconstituted and derivatized with ethanolic 1,2-ethanedithiol. Detection was by GC combined with arsenic selective AED and by electron impact/mass spectrometry (EI/MS) using SIM. Ions monitored were the moderately intense $\mathrm{M}^{+}$ ion at $m / z 228$, an intense ion $\left[\mathrm{M}-\mathrm{C}_{2} \mathrm{H}_{4}\right]^{+}$, $m / z 200$, and a base peak $\left[\mathrm{AsS}_{2} \mathrm{C}_{2} \mathrm{H}_{4}\right]^{+}, \mathrm{m} / z$ 167. The LOD was rather high at $\sim 100$ $\mathrm{ng} / \mathrm{ml}$. CVAA was detected in the urine of guinea pigs up to $24 \mathrm{~h}$ after exposure to lewisite $(0.5 \mathrm{mg} / \mathrm{kg}$ s.c.). Excretion was rapid; a mean concentration of $3.5 \mathrm{ug} / \mathrm{ml}$ was detected in the $0-8 \mathrm{~h}$ urine, which had decreased to $\leq 100 \mathrm{ng} / \mathrm{ml}$ after $16-24 \mathrm{~h}$.
Wooten et al. [18] analyzed CVAA from urine after derivatization with propane1,3-dithiol and the resulting volatile cyclic disulfide was detected by solid phase microextraction (SPME) combined with GC/MS in the SIM mode, but the procedure was not tested on samples from in vivo experiments. The detection limit of CVAA was $7.4 \mathrm{pg} / \mathrm{mL}$ urine.

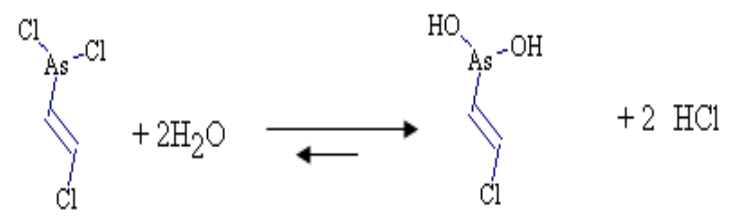

CVAA

Figure no. 3 Hydrolysis process of lewisite

\section{Conclusions}

The last decades underline, at an international level, a rise of awarness of potential attacks/incidents with chemical warfare agents and the development of fast and safe analytical methods of diagnosis for population's exposure to CWA's is in attention of the international organizations and to those that work in the defending system and industry.

\section{References}

1. M. Mesilaakso, Chemical Weapons Convention Chemicals Analysis. Sample collection, preparation and analytical methods, (England: John Wiley \& Sons Ltd, 2005).

2. Presentations by and interviews of Dr. Yasuo Seto, National Research Institute of Police Science, and LTC K. Nakamura, Chemical School Japan Ground Self-Defense Force, CAVTAT, Croatia, (2009).

3. A.T. Tu, "Horrors in Tokyo Subway and Matsumoto City", Chemical Terrorism. Alaken Inc., Fort Collins, Colorado, (2002).

4. E.R.J. Wils, A.G. Hulst, A.L. de Jong, A. Verweij and H.L. Boter, "Analysis of thiodiglycol in urine of victims of an alleged attack with mustard gas", Journal of Analytical Toxicology, 9, Oxford University Press, (1985): 254-257.

5. E.R.J. Wils, A.G. Hulst, and A.G. van Laar, "Analysis of thiodiglycol in urine of victims of an alleged attack with mustard gas", Part II, Journal of Analytical Toxicology, 12, Oxford University Press, (1988): 15-19. 
6. R.M. Black, R.J. Clarke, J.M. Harrison and R.W. Read, "Biological fate of sulfur mustard: identification of valine and histidine adducts in haemoglobin from casulaties of sulfur mustard poisoning", Xenobiotica, 27, Informa - UK, (1997): 499-512.

7. T. Nakajima, K. Sasaki, H. Ozawa, Y. Sekijima, H. Morita, Y. Fukushima and N. Yanagisawa, "Urinary metabolites of sarin in a patient of the Matsumoto sarin incident", Archives of Toxicology, 72, Springer Berlin Heidelberg, (1998): 601-603.

8. D. Noort, A.G. Hulst, D.H.J.M. Platenburg, M. Polhuijs and H.P. Benschop, "Quantitative analysis of O-isopropyl methylphosphonic acid in serum samples of Japanese citizens allegedly exposed to sarin: estimation of internal dosage", Archives of Toxicology, 72, Springer Berlin Heidelberg, (1998): 671-675.

9. H. Tsuchihashi, M. Katagi, M. Tatsuno, M. Nishikawa and A. Miki, "Determination of metabolites of nerve agent O-ethyl-S-2-diisopropylaminoethyl methylphosphothioate (VX), in Natural and Selected Synthetic Toxins", ACS Symposium Series, 745, American Chemical Society, Washington, (2000), 369-386.

10. E.M. Jakubowski Read, F.R. Sidell, R.A. Evans, M.A. Carter, J.R. Keeler, J.D. McMonagle, A. Swift, J.R. Smith and T.W. Dolzine, "Quantification of thiodiglycol in human urine after an accidental sulfur mustard exposure", Toxicology Mechanisms and Methods, 10, United Kingdom, (2000), 143-150.

11. R.M. Black and J.M. Harrison, "The chemistry of organophosphorus chemical warfare agents", in The Chemistry of Organophosphorus Compounds, vol. 4, ed. F.R. Hartley, (New York: John Wiley \& Sons, Ltd, 1996), 781-840.

12. The Organisation for the Prohibition of Chemical Weapons, http://www.opcw.org/

13. M. Minami, D.-M. Hui, M. Katsumata, H. Inagaki and C.A. Boulet, "Method for the analysis of the methylphosphonic acid metabolites of sarin and its ethanol-substituted analogue in urine as applied to the victims of the Tokyo sarin disaster", Journal of Chromatography, B, 695, Elsevier, USA, (1997), 237-244.

14. H. Tsuchihashi, M. Katagi, M. Nishikawa and M. Tatsuno, „Identification of metabolites of nerve agent VX in serum collected from a victim", Journal of Analytical Toxicology, 22, Oxford University Press, (1998), 383-388.

15. N.L. Koryagina, E.S. Ukolova, E.I. Savel'eva, N.G. Voitenko, O.I. Orlova, R.O. Jenkins, and N.V. Goncharov, "High-sensitivity determination of 2-chlorovinylarsonous acid in biomedical samples for retrospective detection of exposure to lewisite upon antidotal therapy", Spectroscopy 26, Hindawi Publishing Corporation, Egypt, (2011), 1-10.

16. E.M. Jakubowski, J.R. Smith, T.P. Logan, N.D. Wiltshire, C.L. Woodard, R.A. Evans, and T.W. Dolzine, "Verification of Lewisite exposure: quantification of chlorovinyl arsonous acid in biological samples", Proceedings of the 1993 Medical Defense Bioscience Review, U.S. Army Medical Research Institute of Chemical Defense, Aberdeen Proving Ground, (1993), 361-368.

17. T.P. Logan, J.R. Smith, E.M. Jakubowski, and R.E. Nielson, "Verification of Lewisite exposure by the analysis of 2-chlorovinyl arsonous acid in urine", Toxicology Mechanisms and Methods, 9, United Kingdom, (1999), 275-284.

18. J.V. Wooten, D.L. Ashley, and A.M. Calafat, "Quantification of 2-chlorovinylarsonous acid in human urine by automated soli-phase microextraction gas chromatography - mass spectrometry", Journal of Chromatography, B, 772, Elsevier, USA, (2002), 147-153.

\section{Bibliography}

Black, R.M., R.J. Clarke, J.M. Harrison, and R.W. Read. "Biological fate of sulfur mustard: identification of valine and histidine adducts in haemoglobin from casulaties of sulfur mustard poisoning”. Xenobiotica, 27, Informa - UK, (1997): 499-512. 
Black, R.M., and J.M. Harrison. "The chemistry of organophosphorus chemical warfare agents". In The Chemistry of Organophosphorus Compounds, vol. 4, ed. F.R. Hartley, 781-840. New York: John Wiley \& Sons, Ltd, 1996.

Dolzine, T.W. "Verification of Lewisite exposure: quantification of chlorovinyl arsonous acid in biological samples". Proceedings of the 1993 Medical Defense Bioscience Review, (10-13 May, 1993): 361-368.

Jakubowski, E., M., Read, F.R. Sidell, R.A. Evans, M.A. Carter, J.R. Keeler, J.D. McMonagle, A. Swift, J.R. Smith and T.W. Dolzine. "Quantification of thiodiglycol in human urine after an accidental sulfur mustard exposure". Toxicology Mechanisms and Methods, 10, United Kingdom, (2000): 143-150.

Jakubowski, E.M., J.R. Smith, T.P. Logan, N.D. Wiltshire, C.L. Woodard, R.A. Evans, and T.W. Dolzine. "Verification of Lewisite exposure: quantification of chlorovinyl arsonous acid in biological samples". Proceedings of the 1993 Medical Defense Bioscience Review, U.S. Army Medical Research Institute of Chemical Defense, Aberdeen Proving Ground, (1993): 361-368.

Koryagina, N.L., E.S. Ukolova, E.I. Savel'eva, N.G. Voitenko, O.I. Orlova, R.O. Jenkins, and N.V. Goncharov. "High-sensitivity determination of 2-chlorovinylarsonous acid in biomedical samples for retrospective detection of exposure to lewisite upon antidotal therapy". Spectroscopy 26, Hindawi Publishing Corporation, Egypt, (2011): 1-10.

Mesilaakso, M. Chemical Weapons Convention Chemicals Analysis. Sample collection, preparation and analytical methods. England: John Wiley \& Sons Ltd, 2005.

Minami, M., D.-M. Hui, M. Katsumata, H. Inagaki and C.A. Boulet. "Method for the analysis of the methylphosphonic acid metabolites of sarin and its ethanol-substituted analogue in urine as applied to the victims of the Tokyo sarin disaster". Journal of Chromatography, B, 695, Elsevier, USA, (1997): 237-244.

Nakajima, T., K. Sasaki, H. Ozawa, Y. Sekijima, H. Morita, Y. Fukushima and N. Yanagisawa. "Urinary metabolites of sarin in a patient of the Matsumoto sarin incident”. Archives of Toxicology, 72, Springer Berlin Heidelberg, (1998): 601-603.

Noort, D., A.G. Hulst, D.H.J.M. Platenburg, M. Polhuijs and H.P. Benschop. "Quantitative analysis of O-isopropyl methylphosphonic acid in serum samples of Japanese citizens allegedly exposed to sarin: estimation of internal dosage". Archives of Toxicology, 72, Springer Berlin Heidelberg, (1998): 671-675.

The Organisation for the Prohibition of Chemical Weapons, http://www.opcw.org/

Seto, Y., National Research Institute of Police Science, and LTC K. Nakamura, Chemical School Japan Ground Self-Defense Force, CAVTAT, Croatia, (2009).

Tu, A.T. "Horrors in Tokyo Subway and Matsumoto City". Chemical Terrorism. Alaken Inc., Fort Collins, Colorado, (2002).

Tsuchihashi, H., M. Katagi, M. Nishikawa and M. Tatsuno. "Identification of metabolites of nerve agent VX in serum collected from a victim". Journal of Analytical Toxicology, 22, Oxford University Press, (1998): 383-388.

Tsuchihashi, H., M. Katagi, M. Tatsuno, M. Nishikawa and A. Miki. "Determination of metabolites of nerve agent O-ethyl-S-2-diisopropylaminoethyl methylphosphothioate (VX), in Natural and Selected Synthetic Toxins". ACS Symposium Series, 745, American Chemical Society, Washington, (2000): 369-386.

Wils, E.R.J., A.G. Hulst, A.L. de Jong, A. Verweij and H.L. Boter. "Analysis of thiodiglycol in urine of victims of an alleged attack with mustard gas". Journal of Analytical Toxicology, 9, Oxford University Press, (1985): 254-257.

Wils, E.R.J., A.G. Hulst, and A.G. van Laar. "Analysis of thiodiglycol in urine of victims of an alleged attack with mustard gas". Part II, Journal of Analytical Toxicology, 12, Oxford University Press, (1988): 15-19. 
Wooten, J.V., D.L. Ashley, and A.M. Calafat. "Quantification of 2-chlorovinylarsonous acid in human urine by automated soli-phase microextraction gas chromatography - mass spectrometry". Journal of Chromatography, B, 772, Elsevier, USA, (2002): 147-153. 